Cahiers $d u$ MONDE RUSSE

\section{Cahiers du monde russe}

Russie - Empire russe - Union soviétique et États indépendants

$43 / 4 \mid 2002$

Intellectuels et intelligentsia

\title{
Laurent Rucker, Staline, Israël et les Juifs
}

\section{Françoise Thom}

\section{OpenEdition \\ Journals}

Édition électronique

URL : https://journals.openedition.org/monderusse/4059

DOI : 10.4000/monderusse.4059

ISSN : $1777-5388$

Éditeur

Éditions de l'EHESS

Édition imprimée

Date de publication : 30 décembre 2002

Pagination : 804-807

ISBN : 2-7132-1796-2

ISSN : $1252-6576$

\section{Référence électronique}

Françoise Thom, "Laurent Rucker, Staline, Israël et les Juifs », Cahiers du monde russe [En ligne], 43/4 | 2002, mis en ligne le 18 juin 2009, consulté le 04 septembre 2022. URL : http://

journals.openedition.org/monderusse/4059; DOI : https://doi.org/10.4000/monderusse.4059

Ce document a été généré automatiquement le 4 septembre 2022

Tous droits réservés 


\title{
Laurent Rucker, Staline, Israël et les Juifs
}

\author{
Françoise Thom
}

\section{RÉFÉRENCE}

Laurent RUCKER, Staline, Israël et les Juifs. Paris, Presses universitaires de France, $2001,380 \mathrm{p}$.

1 Pour ceux qui s'intéressent à l'URSS stalinienne de l'après-guerre, il est peu de sujets aussi passionnants que la politique soviétique à l'égard des juifs durant cette période. Car ce thème met en jeu les relations complexes entre politique intérieure et politique étrangère dans le système communiste; il illustre comment la lutte des clans et les préoccupations du dictateur se combinent ou se combattent dans les décisions adoptées par le Kremlin; comment l'idéologie toujours présente se marie avec l'opportunisme, engendrant des projets provisoires dont les exécutants se retrouvent bientôt sur le banc des accusés. La politique de Stalin à l'égard des juifs est encore plus retorse que ses pratiques habituelles. Laurent Rucker s'est courageusement aventuré dans ces méandres byzantins dessinés autant par les passions intimes d'un homme que par un calcul machiavélique rationnel. Il en résulte un ouvrage clair, posant les bonnes questions et offrant au lecteur non russophone les éléments de réponses que l'ouverture des archives soviétiques a permis d'apporter.

2 Une première partie analyse les raisons pour lesquelles l'URSS, après avoir longtemps hésité, s'est engagée à fond en avril 1947 pour la création d'un État juif en Palestine. Après l'échec de ses tentatives d'expansion en Iran et en Turquie, Stalin n'a pas renoncé à jouer sur les contradictions entre les impérialistes. Consciente que le sort des juifs d'Europe centrale entassés dans les camps de réfugiés est une pomme de discorde entre Américains et Britanniques - les Américains poussant les Britanniques à ouvrir la Palestine à ces rescapés du nazisme -, l'URSS va en 1946 autoriser 150000 juifs polonais à gagner les zones d'occupation américaine et britannique en Allemagne et en Autriche. 
Par haine de l'Angleterre, elle va miser sur la carte du sionisme, traditionnellement dénoncé par la propagande soviétique comme "nationalisme bourgeois». Le choix définitif de l'URSS en faveur de la création d'un État juif a lieu à l'été 1947, c'est-à-dire qu'il est directement lié à l'annonce du plan Marshall et au début de cristallisation du camp occidental. En 1948 Moscou fait pression sur Prague pour que la Tchécoslovaquie cesse de livrer des armes aux Arabes. La Tchécoslovaquie se lance dans une collaboration militaire étroite avec le nouvel État juif, qui permet à celui-ci de remporter la victoire dans la première guerre israélo-arabe. Cette collaboration durera jusqu'en 1951, en dépit de la dégradation des relations entre Israël et l'URSS.

3 Laurent Rucker estime que le désir de saper les positions britanniques au Moyen-Orient fut la principale motivation de la décision de Stalin en faveur de la création de l'État juif. Selon lui, l'espoir d'en faire un bastion socialiste dans la région ne fut pas sérieusement entretenu par le Kremlin. Pourtant la réaction des Soviétiques fut vive lorsqu'ils apprirent début 1949 qu'Israël avait accepté un prêt américain de 100 millions de dollars. Pour eux c'était l'indice qu'Israël était en train de basculer dans le camp américain. Les premiers signes apparents d'un refroidissement entre Israël et l'URSS datent du milieu de l'année 1949. Au fond, la politique juive de Stalin en 1947-1948 montre à quel point il était incapable de tirer les leçons de ses échecs précédents : dans le cas d'Israël comme dans celui de la Turquie et de l'Iran, l'URSS avait agi dans le but d'affaiblir l'Angleterre, en misant sur les "contradictions entre les impérialistes »; et une fois de plus, en s'attaquant à la Grande-Bretagne, elle n'avait fait que renforcer les États-Unis qui pourtant, à partir de 1947, étaient considérés comme l'ennemi principal.

4 Si la politique à l'égard de l'État juif est assez facilement déchiffrable parce qu'elle découle des facteurs permanents de la diplomatie soviétique, celle menée à l'égard des juifs d'Union soviétique est infiniment plus complexe car, dès la guerre et la période de la grande alliance, elle est traversée par des objectifs et des impulsions contradictoires. Il y a d'abord la volonté de faire appel aux juifs américains pour aider Roosevelt à surmonter les fortes réticences Outre-Atlantique à une alliance avec Stalin : c'est ce qui conduira ce dernier à autoriser la création en septembre 1941 du CAJ (Comité antifasciste juif), sur lequel nous reviendrons. Il y a parallèlement le flirt de Stalin avec le nationalisme grand-russe et l'intention de contrer la propagande nazie sur le « judéobolchevisme ». Les premières mesures de "déjudaïsation " de l'establishment culturel soviétique sont prises en 1942. Le conflit entre ces politiques contraires va être accentué par la lutte des clans dans l'entourage de Stalin, le CAJ étant patronné par Molotov influencé par son épouse Åem@uÂina, et par Beria qui joue la carte juive pour des raisons multiples (possibilité d'étendre ses réseaux aux États-Unis, y compris dans la communauté scientifique, sensibilité d'un Mingrélien aux nationalités non russes, et peut-être déjà projet de modernisation de l'URSS avec l'aide financière juive); la carte du nationalisme russe étant, quant à elle, volontiers mise en avant par les protégés de Malenkov.

5 L'auteur consacre un chapitre détaillé à l'histoire du CAJ. Il relève l'aspect mystérieux du faux départ de ce Comité à l'automne 1941 mais, faute de mettre en lumière les liens de cette première mouture du CAJ avec le gouvernement polonais de Londres, ne mesure pas toutes les implications du choix de Beria lorsque celui-ci désigna deux bundistes polonais, Erlich et Alter, pour organiser le CAJ et en définir le programme. La mise en avant de ces deux personnages était un signal à la social-démocratie européenne en même temps qu'un geste de bonne volonté à l'égard du gouvernement Sikorski. En effet, 
les deux hommes entreprirent dès leur libération, et avec la bénédiction du NKVD, de recruter les juifs polonais dans l'armée d'Anders. Or, dès les premiers jours, Sikorski, Anders et Kot - l'ambassadeur polonais à Moscou - étaient persuadés que seul l'appui des juifs de Pologne leur permettrait de restaurer les frontières orientales d'avant-guerre : ils ne pouvaient compter ni sur les Ukrainiens qui misaient alors sur l'Allemagne, ni sur les Biélorusses. L'intégration des juifs polonais dans l'armée d'Anders, la persécution des sionistes polonais menée en même temps par le NKVD, favorisaient objectivement les visées du gouvernement polonais de Londres. Rien d'étonnant donc à ce que Stalin ait promptement mis fin à cette première mouture du CAJ. Le second CAJ de 1942-1943 aura officiellement la tâche de mobiliser les ressources financières des juifs américains pour l'effort de guerre soviétique; il devra aussi neutraliser les efforts du gouvernement Sikorski pour s'assurer l'appui de l'opinion juive américaine. Stalin voulait le soutien des juifs américains pour faire reconnaître à l'URSS les frontières du pacte RibbentropMolotov. C'est pourquoi, dès qu'il obtint gain de cause sur ce point, le CAJ était en sursis.

En février 1944, trois activistes du CAJ adressent à Stalin et Molotov une lettre dans laquelle ils suggèrent de créer une république juive en Crimée. Sur les trois hommes, deux étaient des agents du NKVD. On ne peut donc que rejoindre la conclusion de Laurent Rucker: le projet avait certainement l'aval de Beria. Il reste à deviner les motivations de cette démarche, qui tourna court et que le CAJ paya fort cher, car Stalin ne tarda pas à y voir la preuve de la collusion des juifs soviétiques avec l'impérialisme américain.

7 Enfant de la grande alliance, le CAJ n'était pas destiné à lui survivre longtemps. Cependant le gouvernement soviétique hésita durant toute l'année 1946 à fermer le Comité. On peut mesurer l'intensité des rivalités de clans dans les coulisses du Kremlin aux tribulations du Comité antifasciste durant la période allant de septembre 1946, date de la première proposition de dissoudre le CAJ, à novembre 1948, date de sa fermeture. Les autorités soviétiques faisaient grief au CAJ de se faire le porte-parole des juifs soviétiques au lieu de se borner à la propagande de l'URSS à l'étranger. Aux yeux de Stalin, le CAJ avait commis le péché de devenir un embryon d'organisation représentative. C'était déjà grave, surtout au moment où les juifs soviétiques manifestaient imprudemment leur enthousiasme pour l'État sioniste. Mais ce qui mit Stalin en fureur et lui fit perdre sa prudence coutumière fut la conviction que des fuites dans la presse étrangère sur la vie privée des dirigeants du Kremlin émanaient de Mihoels et de ses proches. Dès qu'il en eut la certitude, Stalin ordonna d'assassiner Mihoels sans tarder. Le même soupçon pesait sur l'épouse de Molotov qu'il fit arrêter en 1949. Molotov ne retrouva jamais sa place privilégiée au sein du Politbjuro.

8 La «lutte contre le cosmopolitisme » lancée en janvier 1949 était le prolongement des campagnes jdanoviennes de 1946. Elle avait pour but de désapprendre aux Soviétiques qu'ils avaient été les alliés des Occidentaux pendant la guerre en stigmatisant les juifs comme des « cosmopolites sans patrie » et donc des traîtres potentiels. Mais à partir de l'assassinat de Mihoels, l'antisémitisme devient aussi un moyen de manipuler Stalin et un instrument dans la lutte pour la succession. La longueur de l'instruction de l'affaire du CAJ (de fin 1948 à juillet 1952), dans laquelle Malenkov joua un rôle visible, la durée de la préparation de l'affaire Slansky, révèlent à la fois l'affrontement des clans et un affaiblissement de la poigne de Stalin. De même, l'affaire du complot des blouses blanches, qui visait à l'origine Abakumov et Beria, fut retournée par celui-ci et Malenkov contre les deux derniers fidèles inconditionnels de Stalin, Poskrebyòev et Vlasik. 
L'offensive projetée par Stalin contre ses collègues du Politbjuro aboutissait en réalité à dégarnir ses flancs. Parallèlement l'hystérie antisémite déclenchée en janvier 1953 achevait de déconsidérer le dictateur dans l'opinion publique occidentale.

9 Ce bref survol du livre de Laurent Rucker ne donne qu'un aperçu de sa richesse et de l'apport qu'il offre à la connaissance des mécanismes du pouvoir soviétique à la fin du règne de Stalin. Certes les zones de mystère demeurent, notamment concernant les derniers mois de sa vie et les objectifs de l'ultime phase de l'affaire des blouses blanches. À lire ce livre, on se rend compte que la politique de Stalin était rationnelle et contrôlée jusqu'à un certain point. Cette rationalité avait deux limites: la fragmentation en clans hostiles de la bureaucratie chargée de mettre en œuvre les directives du dictateur, et les obsessions de Stalin lui-même. La haine de l'Angleterre l'incita à soutenir la création de l'État juif. Sa paranoïa et sa manie du secret se cristallisèrent sur les juifs soviétiques, le poussant à donner son aval à une frénésie antisémite qui réveillait le souvenir des Cent-Noirs et de l'Allemagne nazie, et qui porta un coup fatal au mouvement communiste international. 